Bond University

Research Repository

\title{
Renaming low risk conditions labelled as cancer
}

Nickel, Brooke; Moynihan, Ray; Barratt, Alexandra; Brito, Juan P.; McCaffery, Kirsten

Published in:

BMJ (Online)

DOI:

10.1136/bmj.k3322

Licence:

Unspecified

Link to output in Bond University research repository.

Recommended citation(APA):

Nickel, B., Moynihan, R., Barratt, A., Brito, J. P., \& McCaffery, K. (2018). Renaming low risk conditions labelled as cancer. BMJ (Online), 362, [k3322]. https://doi.org/10.1136/bmj.k3322

\section{General rights}

Copyright and moral rights for the publications made accessible in the public portal are retained by the authors and/or other copyright owners and it is a condition of accessing publications that users recognise and abide by the legal requirements associated with these rights.

For more information, or if you believe that this document breaches copyright, please contact the Bond University research repository coordinator. 


\section{Removing the cancer label from low risk conditions}

Brooke Nickel ${ }^{1,2}$ PhD Candidate, Ray Moynihan ${ }^{1,3}$ Senior Research Fellow, Alexandra Barratt ${ }^{1}$ Professor of Public Health, Juan P Brito ${ }^{4}$ Assistant Professor of Medicine and Senior Associate Consultant, Kirsten McCaffery ${ }^{1,2}$ Behavioural Scientist and Professorial Research Fellow

${ }^{1}$ Wiser Healthcare, Sydney School of Public Health, The University of Sydney, New South Wales, Australia ${ }^{2}$ Sydney Health Literacy Lab, Sydney School of Public Health, The University of Sydney, NSW 2006, Australia ${ }^{3}$ Centre for Research in Evidence-Based Practice, Bond University, QLD 4229, Australia ${ }^{4}$ Knowledge and Evaluation Research Unit, Division of Endocrinology, Diabetes, Metabolism, and Nutrition, Mayo Clinic, MN, USA

Correspondence to: Prof Kirsten McCaffery; Wiser Healthcare, Sydney School of Public Health, The University of Sydney, NSW 2006, Australia. (email: kirsten.mccaffery@sydney.edu.au; phone number: + 6129351 7220)

WORD COUNT: 2342 
STANDFIRST: Brooke Nickel and colleagues consider the evidence that removing the cancer label in very low risk conditions that are unlikely to cause harm if left untreated, may be one helpful strategy to address issues of overdiagnosis and overtreatment

There is a growing body of research showing that disease labels can impact people's psychological responses and their decisions about management options. The use of more medicalised labels can increase both concern about illness and desire for more invasive treatment. ${ }^{1}$ For low risk cancers where there is evidence of overdiagnosis ${ }^{2}$ and calls to replace the term cancer, ${ }^{3-6}$ we consider the potential implication of removing the cancer label.

\section{Our changing understanding of the prognosis of cancers}

Some 'cancers' are non-growing or so slow-growing that they will never cause harm to patients if left undetected. ${ }^{2}$ A prime example of this type of cancer is low risk papillary thyroid cancer. Autopsy studies reveal there is a large reservoir of undetected papillary thyroid cancer that never causes harm ${ }^{7}$ and there is now substantial evidence of a dramatic increase in the incidence of thyroid cancer in many developed countries. This increase has been predominantly driven by an increase in small papillary thyroid cancers, with mortality remaining largely unchanged. ${ }^{8}$ Detection of these small papillary thyroid cancer has mainly been a result of the advent of new technologies, increased access to health services and thyroid cancer screening. ${ }^{5}$ Studies demonstrate that rates of metastases, progression to clinical disease and tumour growth in patients diagnosed with small papillary thyroid cancer who receive immediate surgery are comparable to those who follow active surveillance. ${ }^{910}$

Likewise, for both low risk ductal carcinoma in situ (DCIS) and localised prostate cancer, detection strategies have become controversial as long-term outcomes for both conditions have been shown to be excellent ${ }^{11} 12$ and there is evidence and concern about overdiagnosis and overtreament. ${ }^{2}$ Given 
the potential harms of overtreatment of DCIS, active surveillance is now being trialled internationally as an alternative management approach. ${ }^{13-15}$ Active surveillance is also recognised as a safe and desirable management option for localised prostate cancer in current clinical practice, although invasive procedures such as a prostatectomy are still common and conventional treatment options for men diagnosed with localised disease.

Beyond low risk thyroid cancer, DCIS and prostate cancer, there is some evidence and informed speculation that melanoma in situ, small lung cancers and certain small kidney cancers may be considered low risk cancers and subject to similar overdiagnosis and overtreatment. ${ }^{216-18}$

\section{The cancer label}

For decades 'cancer' has been associated with death. This association has been ingrained in society with public health messaging that 'cancer screening saves lives'. This promotion has been used with the best of intentions, but in part deployed to induce feelings of fear and vulnerability in the population and then offer hope through screening ${ }^{19}$ (Box 1).

While conservative management approaches, such as active surveillance, are becoming an option for some patients with cancer, there is still a strong perception that aggressive treatments are always required. ${ }^{20}$ Recent studies on men diagnosed with localised prostate cancer have found that emotional distress of the diagnosis may motivate men to choose more aggressive treatment. ${ }^{21}$ However, not treating prostate cancer and following active surveillance also increases men's levels of anxiety, rates of depression and fear of cancer recurrence. ${ }^{22}$ Importantly, almost a quarter of men who initially choose to manage their prostate cancer with active surveillance opt for surgery or radiation therapy within 5 years for non-biological reasons. ${ }^{23}$ 


\section{Box 1. Impact of the cancer label}

Widespread enthusiasm for cancer screening

- Landmark US survey found that $87 \%$ of adults believe routine cancer screening is almost always a good idea and $74 \%$ of adults said that finding cancer early (most or all of the time) saves lives. ${ }^{24}$

- A British survey of 2024 men and women aged $50-80$ years found that almost $90 \%$ of people believe that screening is 'almost always a good idea' and $49 \%$ said that they would be tested for cancer even it if was untreatable. ${ }^{25}$

- In studies on breast and cervical cancer it has been shown that women are often highly resistant to the idea of less intensive screening, with concerns about the frequency of screening intervals and that the changes are being made due to cost cutting considerations rather than on the basis of improved evidence about managing the cancer in question. ${ }^{26-28}$

- Interviews with more than 10,000 members of the European public demonstrates that $92 \%$ of women and $89 \%$ of men overestimate (or do not know) the mortality benefit of breast and prostate cancer screening. ${ }^{29}$

Strong desire for surgery

- In a study including healthy US adults it was found that when treatment was framed as being harmful, participants were significantly more inclined to opt for surgery compared to medication ( $65 \%$ v. $\left.38 \%, x^{2}=11.40, p=0.001\right)$, even though doing so may increase their chance of death. ${ }^{20}$

- A study of 394 women found that when ductal carcinoma in situ (DCIS) was described as a non-invasive cancer $47 \%$ of women preferred surgery over non-surgical treatment options such as medication or active surveillance, whereas only $34 \%$ preferred surgery when it was described as 'breast lesion' and $31 \%$ when it was described as 'abnormal cells' $(p \leq 0.001) .^{30}$

Uncertainty around active surveillance of cancer

- In a 5-year nationwide follow-up study it was found that $23 \%$ of men discontinued active surveillance for their low to intermediate risk prostate cancer diagnosis for non-biological reasons ( $20 \%$ patient preference and $3 \%$ other reasons). ${ }^{23}$

\section{Psychological repercussions}

- Across a sample of 1521 men diagnosed with localised prostate cancer it was found that men who were more emotionally distressed at the time of diagnosis were more likely to choose surgery over active surveillance (RRR 1.07; 95\% Cl 1.01, 1.14; $p=0.02$ ). ${ }^{21}$

- A population-based prospective cohort study of 341 men demonstrated that at 9-11 years after diagnosis men who started active surveillance and/or watchful waiting for their low risk localised prostate cancer had higher levels of distress and hyperarousal than men who had radiation or high-dose-rate brachytherapy (AMD $=5.9 ; 95 \% \mathrm{Cl}[0.5,11.3]$ and $A M D=5.4 ; 95 \% \mathrm{Cl}[0.2,10.5]$, respectively) and higher levels of distress and avoidance than men who had low-dose-rate brachytherapy $(A M D=5.3 ; 95 \% \mathrm{Cl}[0.2,10.3]$ and $\mathrm{AMD}=7.0 ; 95 \% \mathrm{Cl}[0.5,13.5]$, respectively). ${ }^{22}$

One potential strategy to calibrate expectation and to avoid unnecessary testing and treatment for these low risk cancers may be to remove the cancer label from conditions unlikely to cause harm if left untreated. This strategy has been proposed by several international experts, ${ }^{3-6}$ including a 
National Institutes of Health state of the science conference panel and a National Cancer Institute working group. In line with this, the chief medical officer of the American Cancer Society Otis W. Brawley has stated: "We need a 21st-century definition of cancer instead of a 19th-century definition of cancer, which is what we've been using. ${ }^{31}$ Notwithstanding the challenges, we agree there is now a clear need to re-label a number of precancerous conditions and low risk cancers (Table 1).

\section{Evidence about labelling supports move to change}

There is now evidence from several studies that describing a condition using more medicalised labels, including the use of the term 'cancer', can lead to an increased preference for more invasive management options (Table 2), ${ }^{1}$ and this supports calls to remove the cancer label, where appropriate. The increased desire for more invasive management may be particularly important to consider in cancers which have a high public profile such as DCIS and prostate cancer. In DCIS it has been shown that women are increasingly opting for more aggressive treatments such as mastectomy and bilateral mastectomy rather than lumpectomy, ${ }^{32}{ }^{33}$ even though these treatments do not improve breast cancer-specific survival. ${ }^{34}$ Similarly, in localised prostate cancer where active surveillance has been a recommended management option for a number of years, studies have shown that the majority of men still prefer to opt for radical prostatectomy or radiation therapy (external-beam radiation or brachytherapy) to manage their diagnosis. ${ }^{23} 35$

How clinicians categorise conditions and recommend treatments may also be influenced by labels. ${ }^{36}$

${ }^{37}$ For clinicians a number of factors may drive them to overdiagnose and overtreat, albeit unconsciously and unintentionally. According to a recent review of the literature, ${ }^{38}$ potential drivers of overdiagnosis in the professional domain include fear of litigation or missing disease, an overemphasis on the need to diagnose, a lack of awareness of potential iatrogenic harms, and the challenge of doing nothing rather than something. Removing the cancer label from low risk 
conditions may help shift clinician perspectives and enable them to feel comfortable recommending less invasive treatment options to patients.

\section{Examples where the cancer label has been removed}

Removing the cancer label from conditions has occurred previously when there is clear evidence that tumours are largely indolent and very unlikely to cause harm (Table 3). An early example of this was when the World Health Organisation and International Society of Urological Pathologists jointly decided to remove the cancer label from bladder tumours. It was agreed by a multidisciplinary group of experts that a condition known to rarely progress to invasive cancer should not be called 'cancer'. In this change papilloma and grade 1 carcinoma of the bladder were reclassified as papillary urothelial neoplasia of low malignant potential. ${ }^{39}$ Similarly, a change in the description of cervical abnormalities found during a Pap smear from cervical intraepithelial neoplasia (ie. cancer), to squamous intraepithelial lesions, using the Bethesda System, has helped support more women to follow active surveillance. This change reflected important advances in the biological understanding of cervical neoplasia as well as advances in cervical screening technology and was driven by a motivation to help provide more uniform, evidence-based, clearer and less anxiety-provoking terminology.$^{40}$

A more recent example of removing the cancer term occurred with 'non-invasive encapsulated follicular variant of papillary thyroid carcinoma' (EFVPT). This condition was shown to behave indolently and rarely exhibit metastases, and was thus reclassified to 'non-invasive follicular thyroid neoplasm with papillary-like nuclear features' (NIFTP).$^{41}$ Under the auspices of the Endocrine Pathology Society working group a panel of international experts largely made up of pathologists reviewed the current criteria of hundreds of cases of patients who had been followed for at least 10 years. Findings demonstrated that none of the patients whose tumours stayed within their capsules had any evidence of cancer and this resulted in agreement to change the label, a decision endorsed 
numerous leading professional societies internationally. To provide simplified and reproducible criteria to assist in the pathological diagnosis of NIFTP the six main consensus nuclear features were grouped together and scored. ${ }^{41}$ The aims of removing the cancer label in this condition were to highlight the indolent nature of the tumour, decrease unnecessary additional therapies ${ }^{42}{ }^{43}$, reduce the potential psychological and financial burden associated with being diagnosed with cancer, and change how clinicians counsel their patients.

Significant as these changes almost certainly have been, we were unable to find any formal evaluation of their impact on practice, clinician behaviour or patient outcomes.

\section{Removing the cancer label}

To help make progress on removing the cancer label from potential low risk conditions, we suggest a number of concrete actions within clinical practice, medical education, and research (Box 2). To start the major reform process of removing the cancer label, we propose an initial global Round Table which could potentially include involvement from key cancer classification and staging groups such as the World Health Organisation (WHO) Classification of Tumours Group, the International Collaboration on Cancer Reporting (ICCR), and the American Joint Committee on Cancer (AJCC), as well as government health agencies and leading professional cancer societies including the National Cancer Institute $(\mathrm{NCl})$ in the United States, the American Cancer Society (ACS), and similar organisations from other nations. We also strongly endorse the inclusion and engagement of both citizens/consumers in initial Round Table discussions and in any subsequent policy decision-making process. Since the identification and treatment of cancer impact the lives of both the public and patients their input and preferences are vital when reaching decisions. In line with contemporary community expectations of independence, formulation of any recommendations for reform would be undertaken in a process free of conflicts of interest. 


\section{Box 2. Actions to help make progress on removing the cancer label \\ Clinical practice}

- Clinicians should initiate discussions about the likely benign nature of low risk conditions, the possibility of overdiagnosis and overtreatment, and the option of less invasive managements such as active surveillance, both before and after diagnostic interventions

- Clinicians should convey risk information using event rates (or absolute risks) in order to show the long-term outcomes for people with low risk conditions, for both active surveillance and immediate treatment, over relevant timeframes such as 10 or 20 years ${ }^{44}$

\section{Medical education}

- Implementation of new medical education curricula can help students and working clinicians gain a deeper understanding of overdiagnosis and strategies to communicate about low risk conditions

- Information should be designed and widely promulgated for the public about overdiagnosis and the benign nature of some low risk conditions.

Research

- Calculation of precise estimates on the proportions of patients affected by changing terminology

- More studies of long-term outcomes of less invasive management options for low risk conditions

- Testing possible alternative labels

Removing the cancer label from some of the low risk candidates (e.g. low risk thyroid cancer and localised prostate cancer) will pose a more challenging task as they display evidence of invasion under the microscope whereas others have no invasive elements (e.g. DCIS). Bringing together a broadly representative multidisciplinary group, such as the one we propose, could start the process of re-labelling by addressing these challenges, as well as current uncertainties and disagreement. Discussions could start by reviewing current evidence on the risk of progression of each of the identified low risk conditions, establishing standardised agreement in pathology reporting and diagnostic criteria across each condition, and then identify - where appropriate - an alternative label that would address the biological and clinical characteristics of the lesion. This process may also have a supplementary effect of enabling pathologists to address and resolve currently concerning levels of disagreement around important thresholds. ${ }^{45} 46$

As history demonstrates change and innovation in medicine are often resisted. ${ }^{47-49}$ Changing something as fundamental as our shared understanding of the nature and meaning of cancer, 
including a change in nomenclature, will therefore face many challenges and barriers, underscoring the need for a multi-stakeholder process. For example, recent qualitative evidence suggests clinicians treating low risk papillary microcarcinomas do not currently see the merits of removing the cancer label. ${ }^{37}$ Similarly focus groups with a random sample of community members found resistance to removing the cancer label from some participants, although a strong openness among many others. ${ }^{50}$

Following a collective approach that involves informed citizens and consumers will provide input and insights - both positive and negative - about how a new label might help recalibrate expectations for detection, follow-up and treatment. For current patients already diagnosed, the impact of a change in a label might have unexpected results. Downgrading a conditions' label may cause patients to revise the nature and extend of follow-up, and question the need for additional treatments which could potentially reduce overtreatment, and any associated harmful psychological effects. ${ }^{1}$ On the other hand, current patients might perceive that a new label undermines their current care, including changing what support they have access to. ${ }^{51}$ Thus, any re-labelling process needs to consider not only the prospective impact of the new label, but also the impact on individuals already diagnosed with the condition, and provide education, support and guidance where necessary in how to proceed.

While it is clear there is a need to re-label some low risk conditions currently labelled as 'cancer', it is vital to be cognisant of the potential to also cause harm. A label may provide beneficial effects including an explanation and symptom validation for those presenting with symptoms, as indicated in other non-cancer conditions. ${ }^{52} 53$ There may also be implications for receiving benefits within the healthcare system, making some individuals ineligible for certain forms of support from government or health insurers. Furthermore, once labelled with cancer, individuals become part of a wider community of cancer survivors. Removing the cancer label could mean many patients may perceive 
that they have been falsely classified, are no longer cancer survivors and may have potentially received unnecessary treatments. This may cause psychological distress and confusion for some patients. As a patient advocate recently suggested, doctors discussing why a change in diagnostic terminology has occurred may help individuals accept such a change. ${ }^{51}$

\section{Moving forward}

'Indolent lesions of low malignant potential' (IDLE) and variations of other similar labels including 'abnormal cells', 'neoplasia' and 'micro-tumour' have been proposed to help convey the favourable prognosis of these lesions, ${ }^{35}$ while others have suggested complete "elimination of the use of the anxiety-producing term carcinoma" for example in the case of DCIS. ${ }^{4}$ Although the label needs to be biologically accurate it also needs to be something patients can understand and that will not induce disproportionate concern. Civil society and consumer involvement in the re-labelling process will be imperative to help ensure that a potential reclassification of these conditions will be understood and supported by the broader community.

Careful consideration, deliberation and endorsement from cancer classification and staging groups, health agencies and cancer societies, as well as major civil society and consumer organisations is needed to begin and move this process forward. We believe that as a starting point, Round Table discussions involving key stakeholder representatives free from conflicts of interests should be considered to establish agreement and ensure that any future change is consistently and uniformly applied. In the meantime, there is much to be done now across clinical, education and research settings.

Ultimately removing the cancer label will create controversy and take time. The end result however will help ensure appropriate evidenced-based care moving forward for both future and current patients. Learning from past examples and planning a formal future evaluation of practice 
implications and patient outcomes is vital to ensuring safe and effective reform. While it remains unclear exactly how to best move forward, it is clear we cannot continue to tell many people they have cancer, when that label may be doing them more harm than good.

\section{KEY MESSAGES:}

- A growing body of research demonstrates that the labels used to describe medical conditions can influence treatment decisions and psychological responses

- Removing the cancer label from low risk conditions that are unlikely to cause harm if left untreated has been proposed by several international experts as one potential strategy to address overdiagnosis and overtreatment, however to date no change has been made

- To start the major reform process, we endorse Round Table discussions involving key cancer classification and staging groups, health agencies, cancer societies and citizens and consumer groups, with participants free from any conflicts of interest

- Learning from past examples and planning a formal evaluation of practice implications and patient outcomes is vital as a way of both evaluating the changes and ensuring safety moving forward

We thank Professor Paul Glasziou for his helpful comments on the manuscript.

COMPETING INTERESTS: RM and AB have been co-chairs of the scientific committee for the Preventing Overdiagnosis conference, which is supported by the BMJ. All other authors declare no competing interests.

CONTRIBUTORS: BN is a PhD candidate with the Wiser Healthcare collaboration at the Sydney School of Public Health. RM is a Senior Research Fellow with the Wiser Healthcare collaboration at the Centre for Research in Evidence-Based Practice at Bond University. AB is a Professor of Public Health with the Wiser Healthcare collaboration at the Sydney School of Public Health. JPB is an Assistant Professor of Medicine and Senior Associate Consultant with the Knowledge and Evaluation Research Unit at the Mayo Clinic. KM is a Behavioural Scientist and Professorial Research Fellow with the Wiser Healthcare collaboration at Sydney School of Public Health. All authors contributed to the concepts and structure of this manuscript. KM is the guarantor.

LICENCE: The Corresponding Author has the right to grant on behalf of all authors and does grant on behalf of all authors, a worldwide licence to the Publishers and its licensees in perpetuity, in all forms, formats and media (whether known now or created in the future), to i) publish, reproduce, distribute, display and store the Contribution, ii) translate the Contribution into other languages, create adaptations, reprints, include within collections and create summaries, extracts and/or, abstracts of the Contribution, iii) create any other derivative work(s) based on the Contribution, iv) to exploit all subsidiary rights in the Contribution, v) the inclusion of electronic links from the Contribution to third party material where-ever it may be located; and, vi) licence any third party to do any or all of the above. 


\section{REFERENCES:}

1. Nickel B, Barratt A, Copp T, et al. Words do matter: a systematic review on how different terminology for the same condition influences management preferences. BMJ open 2017;7(7):e014129. doi: 10.1136/bmjopen-2016-014129

2. Welch HG, Black WC. Overdiagnosis in cancer. Journal of the National Cancer Institute 2010;102(9):605-13. doi: 10.1093/jnci/djq099

3. Esserman $\mathrm{L}$, Thompson IM, Reid B, et al. Addressing overdiagnosis and overtreatment in cancer: a prescription for change. The lancet oncology 2014;15(6):e234-42. doi: 10.1016/S14702045(13)70598-9

4. Allegra CJ, Aberle DR, Ganschow P, et al. NIH state-of-the-science conference statement: diagnosis and management of ductal carcinoma in situ (DCIS). NIH consensus and state-of-the-science statements 2009;26(2):1-27.

5. Brito JP, Morris JC, Montori VM. Thyroid cancer: zealous imaging has increased detection and treatment of low risk tumours. Bmj 2013;347:f4706. doi: 10.1136/bmj.f4706

6. Ostero IJJ, Brodersen J. Do men with lower urinary tract symptoms have an increased risk of advanced prostate cancer? Bmj 2018;361:k1202. doi: 10.1136/bmj.k1202 [published Online First: 2018/05/05]

7. Furuya-Kanamori L, Bell KJ, Clark J, et al. Prevalence of Differentiated Thyroid Cancer in Autopsy Studies Over Six Decades: A Meta-Analysis. Journal of clinical oncology : official journal of the American Society of Clinical Oncology 2016 doi: 10.1200/JCO.2016.67.7419

8. Vaccarella S, Franceschi S, Bray F, et al. Worldwide Thyroid-Cancer Epidemic? The Increasing Impact of Overdiagnosis. The New England journal of medicine 2016;375(7):614-7. doi: 10.1056/NEJMp1604412

9. Ito $\mathrm{Y}$, Miyauchi A, Oda H. Low-risk papillary microcarcinoma of the thyroid: A review of active surveillance trials. Eur J Surg Oncol 2018;44(3):307-15. doi: 10.1016/j.ejso.2017.03.004 [published Online First: 2017/03/28]

10. Jeon MJ, Kim WG, Kwon $\mathrm{H}$, et al. Clinical outcomes after delayed thyroid surgery in patients with papillary thyroid microcarcinoma. European journal of endocrinology / European Federation of Endocrine Societies 2017;177(1):25-31. doi: 10.1530/EJE-17-0160 [published Online First: 2017/04/23]

11. Narod SA, Iqbal J, Giannakeas V, et al. Breast Cancer Mortality After a Diagnosis of Ductal Carcinoma In Situ. JAMA oncology 2015;1(7):888-96. doi: 10.1001/jamaoncol.2015.2510

12. Hamdy FC, Donovan JL, Lane JA, et al. 10-Year Outcomes after Monitoring, Surgery, or Radiotherapy for Localized Prostate Cancer. The New England journal of medicine 2016;375(15):1415-24. doi: 10.1056/NEJMoa1606220

13. Francis A, Fallowfield L, Rea D. The LORIS Trial: Addressing Overtreatment of Ductal Carcinoma In Situ. Clinical oncology 2015;27(1):6-8. doi: 10.1016/j.clon.2014.09.015

14. Elshof LE, Tryfonidis K, Slaets L, et al. Feasibility of a prospective, randomised, open-label, international multicentre, phase III, non-inferiority trial to assess the safety of active surveillance for low risk ductal carcinoma in situ - The LORD study. European journal of cancer 2015 doi: 10.1016/j.ejca.2015.05.008

15. ClinicalTrials.gov. Comparison of Operative to Monitoring and Endocrine Therapy (COMET) Trial For Low Risk DCIS 2017 [Available from: https://clinicaltrials.gov/ct2/show/NCT02926911.

16. Welch HG, Woloshin S, Schwartz LM. Skin biopsy rates and incidence of melanoma: population based ecological study. Bmj 2005;331(7515):481. doi: 10.1136/bmj.38516.649537.E0 [published Online First: 2005/08/06]

17. Mocellin S, Nitti D. Cutaneous melanoma in situ: translational evidence from a large populationbased study. The oncologist 2011;16(6):896-903. doi: 10.1634/theoncologist.2010-0340 [published Online First: 2011/06/03] 
18. Patz EF, Jr., Pinsky P, Gatsonis C, et al. Overdiagnosis in low-dose computed tomography screening for lung cancer. JAMA internal medicine 2014;174(2):269-74. doi: 10.1001/jamainternmed.2013.12738 [published Online First: 2013/12/11]

19. Woloshin S, Schwartz LM, Black WC, et al. Cancer screening campaigns--getting past uninformative persuasion. The New England journal of medicine 2012;367(18):1677-9. doi: 10.1056/NEJMp1209407

20. Fagerlin A, Zikmund-Fisher BJ, Ubel PA. Cure me even if it kills me: preferences for invasive cancer treatment. Medical decision making : an international journal of the Society for Medical Decision Making 2005;25(6):614-9. doi: 10.1177/0272989X05282639

21. Orom H, Underwood W, 3rd, Biddle C. Emotional Distress Increases the Likelihood of Undergoing Surgery among Men with Localized Prostate Cancer. The Journal of urology 2017;197(2):35055. doi: 10.1016/j.juro.2016.08.007

22. Egger SJ, Calopedos RJ, O'Connell DL, et al. Long-term Psychological and Quality-of-life Effects of Active Surveillance and Watchful Waiting After Diagnosis of Low-risk Localised Prostate Cancer. European urology 2017 doi: 10.1016/j.eururo.2017.08.013

23. Loeb S, Folkvaljon Y, Makarov DV, et al. Five-year nationwide follow-up study of active surveillance for prostate cancer. European urology 2015;67(2):233-8. doi: 10.1016/j.eururo.2014.06.010

24. Schwartz LM, Woloshin S, Fowler FJ, Jr., et al. Enthusiasm for cancer screening in the United States. JAMA : the journal of the American Medical Association 2004;291(1):71-8. doi: 10.1001/jama.291.1.71

25. Waller J, Osborne K, Wardle J. Enthusiasm for cancer screening in Great Britain: a general population survey. British journal of cancer 2015;112(3):562-6. doi: 10.1038/bjc.2014.643

26. Kiviniemi MT, Hay JL. Awareness of the 2009 US Preventive Services Task Force recommended changes in mammography screening guidelines, accuracy of awareness, sources of knowledge about recommendations, and attitudes about updated screening guidelines in women ages 40-49 and 50+. BMC public health 2012;12:899. doi: 10.1186/1471-2458-12899

27. Sirovich BE, Woloshin S, Schwartz LM. Screening for cervical cancer: will women accept less? Am J Med 2005;118(2):151-8. doi: 10.1016/j.amjmed.2004.08.021

28. Silver MI, Rositch AF, Burke AE, et al. Patient concerns about human papillomavirus testing and 5-year intervals in routine cervical cancer screening. Obstet Gynecol 2015;125(2):317-29. doi: 10.1097/AOG.0000000000000638

29. Gigerenzer G, Mata J, Frank R. Public knowledge of benefits of breast and prostate cancer screening in Europe. Journal of the National Cancer Institute 2009;101(17):1216-20. doi: 10.1093/jnci/djp237 [published Online First: 2009/08/13]

30. Omer ZB, Hwang ES, Esserman $\amalg$, et al. Impact of ductal carcinoma in situ terminology on patient treatment preferences. JAMA internal medicine 2013;173(19):1830-1. doi: 10.1001/jamainternmed.2013.8405

31. Parker-Pope T. Scientists urge narrower rules to define cancer. Reining in a diagnosis. The New York Times 201323 July.

32. Tuttle TM, Jarosek S, Habermann EB, et al. Increasing rates of contralateral prophylactic mastectomy among patients with ductal carcinoma in situ. Journal of clinical oncology : official journal of the American Society of Clinical Oncology 2009;27(9):1362-7. doi: 10.1200/JCO.2008.20.1681

33. Kummerow KL, Du L, Penson DF, et al. Nationwide Trends in Mastectomy for Early-Stage Breast Cancer. JAMA surgery 2015;150(1):9-16. doi: 10.1001/jamasurg.2014.2895

34. Hwang ES. The impact of surgery on ductal carcinoma in situ outcomes: the use of mastectomy. Journal of the National Cancer Institute Monographs 2010;2010(41):197-9. doi: 10.1093/jncimonographs/Igq032 
35. Cooperberg MR, Broering JM, Carroll PR. Time trends and local variation in primary treatment of localized prostate cancer. Journal of clinical oncology : official journal of the American Society of Clinical Oncology 2010;28(7):1117-23. doi: 10.1200/JCO.2009.26.0133

36. Erueti $C$, Glasziou $P$, Mar CD, et al. Do you think it's a disease? a survey of medical students. $B M C$ Med Educ 2012;12:19. doi: 10.1186/1472-6920-12-19

37. Nickel B, Brito JP, Barratt A, et al. Clinicians' Views on Management and Terminology for Papillary Thyroid Microcarcinoma: A Qualitative Study. Thyroid : official journal of the American Thyroid Association 2017 doi: 10.1089/thy.2016.0483

38. Pathirana T, Clark J, Moynihan R. Mapping the drivers of overdiagnosis to potential solutions. Bmj 2017;358:j3879. doi: 10.1136/bmj.j3879 [published Online First: 2017/08/18]

39. Epstein JI, Amin MB, Reuter VR, et al. The World Health Organization/International Society of Urological Pathology consensus classification of urothelial (transitional cell) neoplasms of the urinary bladder. Bladder Consensus Conference Committee. The American journal of surgical pathology 1998;22(12):1435-48.

40. Solomon D, Davey D, Kurman R, et al. The 2001 Bethesda System: terminology for reporting results of cervical cytology. JAMA : the journal of the American Medical Association 2002;287(16):2114-9.

41. Nikiforov YE, Seethala RR, Tallini G, et al. Nomenclature Revision for Encapsulated Follicular Variant of Papillary Thyroid Carcinoma: A Paradigm Shift to Reduce Overtreatment of Indolent Tumors. JAMA oncology 2016 doi: 10.1001/jamaoncol.2016.0386

42. Hauch A, Al-Qurayshi Z, Randolph G, et al. Total thyroidectomy is associated with increased risk of complications for low- and high-volume surgeons. Annals of surgical oncology 2014;21(12):3844-52. doi: 10.1245/s10434-014-3846-8

43. Iyer NG, Morris LG, Tuttle RM, et al. Rising incidence of second cancers in patients with low-risk (T1N0) thyroid cancer who receive radioactive iodine therapy. Cancer 2011;117(19):4439-46. doi: $10.1002 /$ cncr.26070

44. Trevena LJ, Zikmund-Fisher BJ, Edwards A, et al. Presenting quantitative information about decision outcomes: a risk communication primer for patient decision aid developers. BMC medical informatics and decision making 2013;13 Suppl 2:S7. doi: 10.1186/1472-6947-13-S2S7 [published Online First: 2013/01/01]

45. Elmore JG, Longton GM, Carney PA, et al. Diagnostic concordance among pathologists interpreting breast biopsy specimens. JAMA : the journal of the American Medical Association 2015;313(11):1122-32. doi: 10.1001/jama.2015.1405 [published Online First: 2015/03/18]

46. Elmore JG, Barnhill RL, Elder DE, et al. Pathologists' diagnosis of invasive melanoma and melanocytic proliferations: observer accuracy and reproducibility study. $\mathrm{Bmj}$ 2017;357:j2813. doi: 10.1136/bmj.j2813 [published Online First: 2017/07/01]

47. Hazan A. Ignaz Semmelweis and the lessons of fear and medical innovation 2014 [Available from: https://www.kevinmd.com/blog/2014/05/ignaz-semmelweis-lessons-fear-medicalinnovation.html accessed 16 July 2018.

48. Altman LK. Nobel Came After Years of Battling the System. The New York Times 200511 October 2005.

49. Pope C. Resisting Evidence: The Study of Evidence-Based Medicine as a Contemporary Social Movement. Health: An Interdisciplinary Journal for the Social Study of Health, IIIness and Medicine 2003;7(3):267-82. doi: https://doi.org/10.1177/1363459303007003002

50. Semsarian C, Nickel B, Moynihan R, et al. Public perceptions of thyroid cancer overdiagnosis, overtreatment and communication strategies: a qualitative study. Sydney Cancer Conference. Sydney, Australia, 2018.

51. Syrett S. Why a change of diagnosis shouldn't matter . . but it does. Bmj 2018;361:k1472. doi: 10.1136/bmj.k1472 [published Online First: 2018/04/14] 
52. Avery JC, Braunack-Mayer AJ. The information needs of women diagnosed with Polycystic Ovarian Syndrome--implications for treatment and health outcomes. BMC women's health 2007;7:9. doi: 10.1186/1472-6874-7-9

53. Anderson VR, Jason LA, Hlavaty LE, et al. A review and meta-synthesis of qualitative studies on myalgic encephalomyelitis/chronic fatigue syndrome. Patient education and counseling 2012;86(2):147-55. doi: 10.1016/j.pec.2011.04.016

54. Copp T, McCaffery K, Azizi L, et al. Influence of the disease label 'polycystic ovary syndrome' on intention to have an ultrasound and psychosocial outcomes: a randomised online study in young women. Human reproduction 2017:1-9. doi: 10.1093/humrep/dex029

55. McCaffery K, Nickel B, Moynihan R, et al. How different terminology for ductal carcinoma in situ impacts women's concern and treatment preferences: a randomised comparison within a national community survey. BMJ open 2015;5:e008094. doi: 10.1136/bmjopen-2015-008094

56. Scherer LD, Zikmund-Fisher BJ, Fagerlin A, et al. Influence of "GERD" label on parents' decision to medicate infants. Pediatrics 2013;131(5):839-45. doi: 10.1542/peds.2012-3070

57. Scherer LD, Finan C, Simancek D, et al. Effect of "Pink Eye" Label on Parents' Intent to Use Antibiotics and Perceived Contagiousness. Clinical pediatrics 2015 doi: 10.1177/0009922815601983

58. Azam N, Harrison M. Patients' perspectives on injuries. Emerg Med J 2011;28(7):601-3. doi: 10.1136/emj.2009.082032 
Table 1. Examples of candidate tumour types that could be considered for re-labelling

\begin{tabular}{|c|c|c|c|c|}
\hline Type of cancer & $\begin{array}{l}\text { Risk of tumour } \\
\text { progression }\end{array}$ & $\begin{array}{l}\text { Disease-specific } \\
\text { mortality }\end{array}$ & $\begin{array}{l}\text { Conventional treatment } \\
\text { options }\end{array}$ & $\begin{array}{l}\text { Harms associated with invasive } \\
\text { treatments }\end{array}$ \\
\hline $\begin{array}{l}\text { Intrathyroidal } \\
\text { papillary thyroid } \\
\text { cancer }(<1 \mathrm{~cm} \text { in } \\
\text { size) }\end{array}$ & $\begin{array}{l}3.8 \% \text { over a period } \\
\text { of } 10 \text { or more } \\
\text { years }\end{array}$ & $<1 \%$ at 20 years & $\begin{array}{l}\text { Thyroidectomy; hemi- } \\
\text { thyroidectomy }\end{array}$ & $\begin{array}{l}\text { Surgical complications including } \\
\text { problems with voice and calcium } \\
\text { levels; need for life-long thyroid } \\
\text { hormone replacement medication } \\
\text { and its associated side-effects; out- } \\
\text { of-pocket costs; psychological } \\
\text { harms }\end{array}$ \\
\hline $\begin{array}{l}\text { Low and } \\
\text { intermediate grade } \\
\text { DCIS (stage } 0 \\
\text { breast cancer) }\end{array}$ & $\begin{array}{l}\sim 14-53 \% \text { over a } \\
\text { period of } 10 \text { or } \\
\text { more years }\end{array}$ & $\begin{array}{l}\text { Breast cancer- } \\
\text { specific mortality } \\
\text { rate is } 3.3 \% \text { at } 20 \\
\text { years }\end{array}$ & $\begin{array}{l}\text { Lumpectomy +/- } \\
\text { radiotherapy; mastectomy } \\
\text { +/- reconstruction }\end{array}$ & $\begin{array}{l}\text { Surgical complications including } \\
\text { persistent pain; lymphedema; skin } \\
\text { burns; long-term cardiovascular } \\
\text { and pulmonary toxicity; out-of- } \\
\text { pocket costs; psychological harms }\end{array}$ \\
\hline
\end{tabular}


Table 2.

\begin{tabular}{|c|c|c|c|c|c|c|}
\hline Study & More medical labelt & & Less medical label & & & p-value \\
\hline Copp, $2017^{54}$ & Polycystic ovary syndrome & 70 & Hormonal imbalance & 53 & 17 & $>0.05$ \\
\hline $\begin{array}{l}\text { McCaffery, } \\
2015^{55}\end{array}$ & 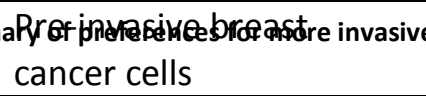 & inger & nAbn日semal cells & 33 & 7 & 0.23 \\
\hline Omer, $2013^{30}$ & Non-invasive cancer & 47 & Lesion, abnormal cells & 32.5 & 14.5 & $<0.001$ \\
\hline $\begin{array}{l}\text { Scherer, } \\
2013^{* * 56}\end{array}$ & $\begin{array}{l}\text { Gastro-oesophageal reflux } \\
\text { disease (GERD) }\end{array}$ & 74 & No label & 67 & 7 & $>0.1$ \\
\hline $\begin{array}{l}\text { Scherer, } \\
2015^{* * 57}\end{array}$ & Pink-eye & 60 & Eye infection & 58 & 8 & $>0.1$ \\
\hline Azam, $2010^{58}$ & $\begin{array}{l}\text { Broken bone, fracture, } \\
\text { greenstick fracture, } \\
\text { hairline fracture }\end{array}$ & 39 & Crack in the bone & 20 & 20 & $<0.025$ \\
\hline
\end{tabular}

*adapted from Nickel et al, 2017; ${ }^{1}$ data combined where applicable and mean percentages reported

**significant two-way interaction between the more medical label and interest in ineffective medications

found in the study

Table 3. Examples of where the cancer label has been previously removed or changed

\begin{tabular}{|l|l|l|l|l|}
\hline Original nomenclature & New nomenclature & $\begin{array}{l}\text { Year of } \\
\text { change }\end{array}$ & Group/s initiating change & Reason for change \\
\hline $\begin{array}{l}\text { Papilloma and grade 1 } \\
\text { carcinoma of the bladder }\end{array}$ & $\begin{array}{l}\text { Papillary urothelial neoplasia } \\
\text { of low malignant potential }\end{array}$ & 1998 & $\begin{array}{l}\text { The World Health } \\
\text { Organisation \& } \\
\text { International Society of } \\
\text { Urological Pathology }\end{array}$ & $\begin{array}{l}\text { To provide better correlation } \\
\text { of these lesions with their } \\
\text { biologic behaviour using } \\
\text { uniform technology }\end{array}$ \\
\hline $\begin{array}{l}\text { Cervical Intraepithelial } \\
\text { Neoplasia (CIN)* }\end{array}$ & $\begin{array}{l}\text { Squamous Intraepithelial } \\
\text { Lesion (SIL) }\end{array}$ & 2001 & $\begin{array}{l}\text { The Bethesda System } \\
\text { Workshop Group } \\
\text { (initiated by the Division } \\
\text { of Cancer Prevention and } \\
\text { Control, National Cancer } \\
\text { Institute) }\end{array}$ & $\begin{array}{l}\text { To reflect important advances } \\
\text { in biological understanding of } \\
\text { cervical neoplasia and cervical } \\
\text { screening technology }\end{array}$ \\
\hline $\begin{array}{l}\text { Non-invasive encapsulated } \\
\text { follicular variant of papillary } \\
\text { thyroid carcinoma (EFVPTC) }\end{array}$ & $\begin{array}{l}\text { Non-invasive follicular thyroid } \\
\text { neoplasm with papillary-like } \\
\text { nuclear features (NIFTP) }\end{array}$ & 2016 & $\begin{array}{l}\text { The Endocrine Pathology } \\
\text { Society working group }\end{array}$ & $\begin{array}{l}\text { To highlight the low risk of } \\
\text { adverse outcome of this } \\
\text { tumour and reduce } \\
\text { psychological and clinical } \\
\text { consequences associated } \\
\text { with the diagnosis }\end{array}$ \\
\hline
\end{tabular}

*original nomenclature still being used in the UK 